\title{
Does the London Stock Exchange require an Upstairs Market? Evidence from Block Trades
}

\section{Introduction}

Liquidity for large trades is provided by trading them through upstairs brokers. These brokers have the power to agree outside-the quote execution at times when liquidity in standard equity markets is lacking. The objective of the upstairs market is that it increases market liquidity because participants are granted flexibility to trade large transactions outside the bid and ask quotes. This is the case in a vast proportion of the major stock exchanges throughout the world. One notable exception is the London Stock Exchange (LSE), where all trades regardless of size are traded on a standard equity market, known as a downstairs market. In this paper we test if the LSE requires an upstairs market by examining the relationship between large trades and market liquidity for different trade sizes. Large trades are defined in the academic literature by Gregoriou (2008) as block trades, which are transactions of 10,000 shares or more.

It is vital that we examine the relationship between block trade sizes and market liquidity, because block trades encapsulate over $60 \%$ of the entire trading volume in international equity markets. ${ }^{1}$ This is because institutional trades consist mainly of block transactions. Previous literature finds no international evidence of an association between the size of block trade and market liquidity. Madhavan and Cheng (1997) find no significant impact of block sizes on market liquidity in US equity markets. They attribute

\footnotetext{
${ }^{1}$ The Financial Times, January 2006.
} 
their findings to the liquidity gains via the execution of block trades through an upstairs market. Bessembinder and Venkataraman (2004) re-affirm the Madhavan and Cheng (1997) findings for the French equity market. Chakravarty (2001) and Alzahrani et al (2013) also provide evidence that order size and execution results in corresponding trade price impact in developed (US) and developing (Saudi) stock markets.

The only study on the LSE on block size and market liquidity is provided by Gemmill (1996). He finds a nonlinear relationship between market liquidity and block size. This is because a large trade reduces the fixed trading cost per share due to economies of scale, but it increases both the risk-premium required on inventory and on the possibility of the transaction being based upon private information. The result is that market liquidity captured by bid-ask spreads at first decrease with block size and then increase, as the risk premium becomes significant. Therefore, the overall impact on market liquidity of trade size depends on the relative magnitude of the changes in these two components. ${ }^{2}$

The major shortcoming of all the existing literature on block trades and market liquidity is that block sizes are typically partitioned into categories of 10,000 to 20,000 , 20,000 to 50,000 and greater than 50,000 shares. The problem with this approach is that a significant proportion of block transactions (approximately $30 \%$ in the LSE) are greater than 50,000 shares. The considerable variation in block sizes, suggest that the coefficient representing 50,000 shares or more, may not provide reliable estimates of the relationship between market liquidity and block size for large block trades. In addition to concealing

\footnotetext{
${ }^{2}$ There is a vast amount of academic literature on block trades in general over the last twenty years. These studies are not mentioned in this paper due to irrelevance in determining the relationship between block size and market liquidity.
} 
block size information, the effect of pooling all block trades with sizes in excess of 50,000 shares, is that the pooled effects may not even provide consistent estimates of the average (Pesaran and Smith, 1995). This is of particular importance in the LSE because there is no upstairs market to capture hidden liquidity achieved by executing block trades outside the bid and ask quotes.

In this paper we test the validity of the pooling assumption of block trade sizes in the LSE. The objective is to determine whether the partitioning of block sizes in the previous literature provides a true representation of the empirical relationship between the size of block trades and market liquidity in the LSE. The test results suggest that the pooling hypothesis cannot be rejected for the categories of 10,000 to 20,000 , and 20,000 to 50,000 shares. However, we find overwhelming evidence that block trades of 50,000 shares or more cannot be pooled. Further econometric analysis reveals that liquidity is dramatically reduced for large block transactions consisting of trades in excess of 500,000 shares. Our empirical findings suggest that the LSE may require a specialist upstairs market which obtains liquidity for large block transactions, by allowing trading to occur outside the market makers' ask and bid quotes.

The rest of the paper is organised as follows. The following section discusses the econometric specification; Section 3 discusses data and the tests of poolability; section 4 presents the empirical results; and section 5 summarises and concludes. 


\section{Econometric Specification}

In order to conduct our empirical analysis we follow the mainstream literature on block trades and liquidity by estimating a similar model to Heflin and Shaw (2000). We augment their econometric specification by incorporating a block size variable in a multivariate testable relationship of the following form: ${ }^{3}$

$$
S_{j, i}=\lambda_{0 i}+\lambda_{1} \text { Size }_{i}+\lambda_{2} P_{i}+\lambda_{3} M_{i}^{v}+\lambda_{4} V_{i}^{o l}+\varepsilon_{i}
$$

Where, $S_{j}$ denotes the different measures of market liquidity $(j=1, \ldots, 3)$; and i represents each block trade that was executed on the LSE in 2010. We proxy market liquidity through three measures of bid-ask spread, namely, the relative bid-ask spread, the effective bid-ask spread and the Huang and Stoll (1997) measure of the adverse selection cost component of bid-ask spread. ${ }^{4}$ A brief discussion of these liquidity measures and their computational details are given in section 3. Size, $P, M^{V}$ and $V^{O L}$ correspondingly denote block size, share prices, market value of the company, and stock market volatility. Share price is the execution price of the block trade; firm size is the market value of the firm's common equity; stock market volatility is proxied by the rolling (fortnightly) standard deviation of stock return. All the variables are expressed in natural logarithms in

\footnotetext{
${ }^{3}$ We prefer to estimate the Heflin and Shaw (2000) rather than the Gemmill (1996) model, because they include relevant statistically significant control variables in the empirical specification of market liquidity and block size in a multivariate framework.

${ }^{4} \mathrm{We}$ use liquidity to represent a proxy for trading costs. We accept that there are alternative measures of trading costs such as commission charges paid to traders. However, commission data is very subjective and is also not available for block trades as far as we are aware. Therefore like all the previous literature on market microstructure, we use liquidity to approximate transaction costs of block trades.
} 
order to minimize the impact of excess skewness and kurtosis in the data. ${ }^{5}$ In specification (1), a negative and significant $\lambda_{1}$ for all bid-ask spreads (liquidity) imply that block trades, increase market liquidity because large trades reduce the fixed trading cost per share due to economies of scale. On the other hand, a positive and significant $\lambda_{1}$ for all bid-ask spread (liquidity) suggests that block trades decrease market liquidity by increasing the risk premium required on inventory and/or the risk of trading with informed agents for market makers.

\section{Data Description and Block Size Heterogeneity}

\subsection{Dataset}

Our sample consists of all block trades defined as transactions of 10,000 shares or more, executed on the LSE in 2010. There are 2.32 million intraday observations. Several filters are applied to the block trades and quotes. ${ }^{6}$ We obtain all our data directly from the LSE. $^{7}$ We use three bid-ask spread measures to proxy the liquidity of block trades. The first measure is the relative bid-ask spread defined as the ask price minus the bid price divided by the average of the bid and ask prices. Given that approximately $20 \%$ of the block trades in our sample occur within the bid and ask quotes we compute the effective spread, the second measure of liquidity.

The effective spread is measured as twice the absolute value of the difference between a transaction price and the midpoint of the bid and asks quotes at the time of transaction. Extensive theoretical literature (see among others Huang and Stoll, 1997 and

\footnotetext{
${ }^{5}$ The descriptive statistics showing excess skewness and kurtosis on the raw data are available from the authors upon request.

${ }^{6}$ We eliminate trades with negative or zero bid-ask spreads. This is because these block trades have not actually been traded.

${ }^{7}$ We would like to thank the LSE for providing us with the dataset.
} 
Madhavan, Richardson and Roomans, 1997) decomposes trading costs into its noninformation and information components. The non-information component comprises the direct costs of inventory holding and order processing while the information component is associated with the costs of asymmetric information. The latter is commonly known as the adverse selection costs of trading. Its isolation and use in modelling market liquidity reveals the magnitude of the influence of asymmetric information on trading costs.

We compute the adverse selection component of total trading costs following the method of Huang and Stoll (1997, henceforth HS). ${ }^{8}$ The HS adverse selection component is computed by estimating the following regression by ordinary least squares at firm level:

$$
\text { price }_{t}=\beta_{1} Q_{t}+\beta_{2} Q_{t-1}+\beta_{3} Q_{A, t-1}+\varepsilon_{t}
$$

Where $\Delta$ price $_{t}$ represents the change in the transaction price prior to the quoted spread at time $t ; Q_{i, t}$ equals $1(-1)$ if the trade is a sell (buy) at time $t$. Following Heflin and Shaw (2000) we use a "combined" buy/sell indicator, $Q_{A, t-1}$, which equals $1(-1,0)$ if the sum of $Q_{i, t-1}$ across all the block trades is positive (negative, zero) to capture the market-wide pressure on the inventory cost component of the bid-ask spread. Assuming that the

\footnotetext{
${ }^{8}$ One possible limitation of the present study is that alternative spread decomposition models were not considered. However, as pointed out by Van Ness et al (2001) all spread decomposition models yield very similar results.
} 
number of block purchases and sales are equal, the estimated information cost component of the bid-ask spread is equal to $2\left(\beta_{2}+\beta_{1}\right){ }^{9}$

Table 1 provides descriptive statistics for the block trade sizes analyzed in this study. The overall sample consists of 2,323,250 block trades, of which 1,233,124 are block purchases and 1,094,356 are block sales. The sample is extremely large when compared to previous studies on market liquidity and block size. For example Madhavan and Cheng (1997) examined 16,343 US blocks while Gemmill (1996) analyzed 5,987 blocks on the LSE. The average size of purchase ( $£ 4.33$ million) is slightly smaller than the average size of sales (4.66 million). We also witness that block trades account for 62 and 59 percent of the equity of the firms in our sample for purchases and sales, respectively. This further highlights the importance of block trades in the LSE. ${ }^{10}$

\section{[INSERT TABLE 1 HERE]}

\subsection{Block Size Heterogeneity}

The distribution of sizes of block trades for our sample can be witnessed in Table 2. We observe that block trades are extremely heterogeneous across sizes. The most important characteristic is that approximately $30 \%$ of total trading volume in block trades, stem from block transactions in excess of 50,000 shares, with a vast proportion (18\%) coming from block trades of 500,000 shares or more. It is, therefore, vital to formally test if it is valid to pool the dataset and estimate a single block trade and

\footnotetext{
${ }^{9}$ Huang and Stoll (1997) develop a technique using an estimated trade reversal probability as an alternative to the aggregate buy/sell indicator but this measure can produce negative empirical estimates of the information cost component of the bid-ask spread. Hence, we follow Heflin and Shaw (2000) to decompose spread utilizing the aggregate buy/sell indicator.

${ }^{10}$ Note we have descriptive statistics for all the other variables displayed in Equation (1). These are not reported because the main focus of the paper is on the heterogeneity of block trade sizes. However, the authors are happy to provide the descriptive statistics for all the other variables upon request.
} 
liquidity relationship for large block trades, where large block trades are defined as trades in excess of 50,000 shares by the previous literature.

\section{[INSERT TABLE 2 HERE]}

We investigate data poolability through the tests of parameter homogeneity. We estimate Equation (1) and test the null of parameter $\left(\lambda_{1}\right)$ equality for trade sizes between 10,000 to 20,000 shares, 20,000 to 50,000 shares and shares in excess of 50,000. We explicitly test poolability across these categories because the previous literature always partitions block trades into one of the three size groups. If the null hypothesis is not rejected across the sample of categories, then that forms a basis for pooling the block size data because this essentially implies homogeneity in the block trade and liquidity relationship within each trade size group. We then test for the null of group-wise error homocsedasticity treating each trade size category as a separate entity. A rejection of group-wise homoscedasticity indicates that the block trade size category heterogeneity is dynamic.

Chow $\mathrm{F}$ tests under the null of parameter equality across trade sizes between 10,000 to 20,000 shares, 20,000 to 50,000 shares and shares in excess of 50,000 are reported in Table 3. We observe that the null hypothesis is accepted across trade sizes between 10,000 to 20,000 shares and 20,000 to 50,000 shares, but is rejected for shares in excess of 50,000. The results remain intact for all three measures of liquidity. Hence, the parameters of Equation (1) are different across large block trades. The LM tests of groupwise homoscedasticity are also reported in Table 3, which confirm that error variances across small and medium block trade transactions (10,000 to 20,000 and 20,000 to 50,000 shares) are the same (i.e., homoscedastic), whereas large block trades in excess of 50,000 
shares have significantly different error variances across the trades (i.e., heteroscedastic). Thus, the elasticity of block liquidity (spreads) with respect to block trade size for large transactions is different; the error dynamics across large block transactions are also significantly different. These results hold across all three measures of spreads. Consequently, there is overwhelming evidence that large block transactions of 50,000 shares or more cannot be pooled in the LSE. This implies that a single regression examining the empirical association between the liquidity and size of block trades is suitable across small and medium transactions, but is not applicable to block trades in excess of 50,000 shares.

\section{[INSERT TABLE 3 HERE]}

Motivated by the block trade size distribution results displayed in Table 2, we allocate each large block transaction of 50,000 shares or more into four groups, which are defined as 50,000-100,000 shares, 100,000-500,000 shares, 500,000-1,000,000 shares, and shares in excess of $1,000,000$.

Chow $\mathrm{F}$ tests under the null of parameter equality across the decomposition of the large block transactions between 50,000 to 100,000 shares, 100,000 to 500,000 shares, 500,000 to $1,000,000$ shares and shares in excess of 1,000,000 are reported in Table 4. We observe that the null hypothesis is accepted across all the decompositions of large block trade sizes, for all three measures of liquidity. Hence, the parameters of Equation (1) are the same across all large block trades. The LM tests of group-wise homoscedasticity are also reported in Table 4, which confirm that error variances across all large block trade transactions are the same (i.e., homoscedastic). Thus, the elasticity of block liquidity (spreads) with respect to block trade size across large transactions is not 
significantly different. Therefore it is appropriate to run a single regression of block size and liquidity for block trades across the four groups of large block transactions that are displayed above.

\section{[INSERT TABLE 4 HERE]}

\section{Empirical Results}

As a result of the parameter equality results across different block trade sizes displayed in Table 3, we initially provide empirical estimates of Equation 1 for trade sizes between 10,000 to 20,000 shares and 20,000 to 50,000 shares. The results (reported in Table 5) indicate a negative relationship between block sizes and the bid-ask spread. This implies that as a result of increasing economies of scale from the trading of a vast quantity of shares at any given time, market makers reduce the bid-ask spread. The results also suggest that market makers do not reduce spreads due to their possible dealings with uninformed traders, because the negative relationship between block trade sizes and the bid-ask spread remains intact for the adverse selection component of the bid-ask spread. The control variables are all highly significant with the hypothesized sign. Market value of the company appears negative and significant suggesting that the larger the companies the lower tends to be the spread of block trades. We also find some evidence that as we raise the size of the trade that the magnitude of the market value coefficient increases in real terms. This suggests that larger trades are associated with larger companies, which is logical as institutional trades are associated with the largest companies listed on the FTSE. Stock return volatility appears positive and significant 
suggesting that increased return volatility increases the costs of block trading. We find weak evidence that the degree of the stock return volatility coefficient escalates as the trade size increases, which implies that there is a bigger risk when investors are trading larger quantities of stock. This is consistent with market microstructure theory as the inventory holding costs increase as you trade larger amounts of equity. Share price appears negative and significant which suggests a decrease in trading costs during stock market rally. There is strong evidence that the magnitude of the negative association between share prices and liquidity is enhanced when trade size goes up. This suggests that there is a decrease in transaction costs due to momentum trading. Finally, the residuals are normally distributed for all empirical models suggesting that our econometric estimates are not due to outliers in the data.

\section{[INSERT TABLE 5 HERE]}

Based on the poolability results displayed in Table 4, we display the econometric estimates of Equation 1 for trade sizes between 50,000 to 100,000 shares and 100,000 to 500,000 shares, 500,000 to $1,000,000$ and in excess of $1,000,000$ shares in Table 6 . We find that the trade size variable is positive and highly significant at all conventional levels. This suggests that there is a positive relationship between the block size and the bid-ask spread. Our results indicate that for large block transactions there is a lack of liquidity in the market due to the difficulty that market makers face in attracting counter parties for the execution of trades. This encourages market makers to increase the bid-ask spread in order to receive adequate compensation for the risk in not being able to execute trades. The findings are driven by a lack of liquidity rather than market makers dealing 
with informed traders, because the positive relationship continues to exist when we look at the adverse selection component of the bid-ask spread. We also find that the magnitude of the block size coefficient increases with the size of the trade. This indicates that the larger the block size, the less liquidity in the financial market. The significance and sign of the control variables displayed in Table 5 remain intact. Finally, the normality in the residuals shows that our findings are not due to outliers in the data.

\section{[INSERT TABLE 6 HERE]}

\section{Conclusion}

It is a common feature in international equity markets that large transactions defined in the academic literature as block trades, are traded on an upstairs market. This enables market makers to obtain liquidity by negotiating transaction prices outside the bid and ask quotes, due to a lack in the liquidity for these large trades in the financial markets. A notable exception to the presence of an upstairs market is the London Stock Exchange. This is because block trades are traded like any standard share in a conventional equity market, known as a downstairs market. In this paper we directly test whether the London Stock Exchange requires an upstairs market for the execution of block trades. We do this by testing if different block sizes can be pooled. Our findings provide overwhelming evidence that large block trades cannot be pooled. This suggests that they should be analyzed in different categories to the rest of the block trades.

Our econometric analysis of the empirical relationship between block trade sizes and market liquidity reveals on the one hand, that for block transactions of 50,000 shares or less, there is a negative relationship between the size of the trade and market liquidity. 
On the other hand, for block trades in excess of 50,000 shares, there is a positive association between the size of the trade and market liquidity. We show that for small and medium block trades, liquidity is enhanced due to the increasing economies of scale that market makers are faced with as a result of trading large quantities of shares. For large block trades, there is a positive relationship between market liquidity and the size of a trade. This is because market makers increase the bid-ask spread in order to receive adequate compensation for the risk of not being able to execute trades, due to lack of liquidity in the market. We also find that the magnitude of the block size coefficient increases with the size of the trade. This indicates that the larger the block size, the less liquidity in the financial market. Finally, we demonstrate that informed trades are not driving the changes in market liquidity. Our empirical findings imply that for larger transactions in excess of 50,000 shares, liquidity could be enhanced if a specialist upstairs market is implemented on the London Stock Exchange. However, as pointed out by Christie et al (1994) even in the presence of an upstairs market on the NASDAQ, liquidity can be low due to the collusion of market makers in order to maintain wider bidask spreads of block trades.

An interesting avenue for further research would be to establish a block trade size that would solicit upstairs market intervention for liquidity. If the ideal block size can be found, then a possibility exists that this block size could serve as the optimal large block for the London Stock Exchange and other global stock markets to create their units for institutional traders. Frequent intervention by specialists for liquidity supply is expensive and may cause unforeseen disruption due to large transactions. If securities can be designed to avoid liquidity shock-injection, smoothness of block trading may resume 
without an outsider's help. This would promote the trading market to dictate supply and demand of large block trades. A formal investigation on the optimal block trade size for the adoption of an upstairs market would provide a substantial contribution to the literature on market microstructure of institutional trades. ${ }^{11}$

\section{References}

Alzahrani, A, A. Gregoriou and R.Hudson (2013), "Price Impact of Block Trades in the Saudi Stock Market", Journal of International Financial Markets, Institutions and Money, 23, 322-341.

Bessembinder, H, and K. Venkataraman, (2004), "Does an electronic stock exchange need an upstairs market?" Journal of Financial Economics, 73, 3-36.

Cakravarty, S. (2001), “Stealth-Trading: Which Trades' Trades Move Stock Prices?" Journal of Financial Economics, 61, 289-307.

Christie, W.G and P.H. Schultz (1994) "Why do NASDAQ market makers avoid oddeighth quotes?" Journal of Finance, 49, 1813-1840.

Gemmill, G., (1996), "Transparency and Liquidity: A Study of Block Trades in the London Stock Exchange under Different Publication Rules”, Journal of Finance, 51, 1765-1790.

Gregoriou, A, (2008) "The asymmetry of the price impact of block trades and the bid-ask spread”, Journal of Economic Studies, 35, 191-199.

Heflin, F, and K.W. Shaw (2000), "Blockholder Ownership and Market Liquidity", Journal of Financial and Quantitative Analysis, 35, 621-633.

\footnotetext{
${ }^{11}$ We thank an anonymous referee for making this suggestion.
} 
Huang, R.D, and H.R. Stoll (1997), “The Components of the Bid-Ask Spread: A General Approach”, Review of Financial Studies, 10, 995-1034.

Madhavan, A., and M.Cheng, (1997) "In search of liquidity: Block trades in the upstairs and downstairs markets", Review of Financial Studies, 10, 175-204

Madhavan, A, M. Richardson, and M. Roomans, (1997) "Why do Security Prices Change? A transaction-level analysis of NYSE stocks", Review of Financial Studies, 10, 1035-1064.

M.H. Pesaran and R.Smith (1995) "Estimating long-run relationships from dynamic heterogeneous panels", Journal of Econometrics, 68, 79-113.

Van Ness, B.F, R.A. Van Ness and R.S.Warr. (2001) "How Well Do Adverse Selection Components Measure Adverse Selection?" Financial Management, 30, 77-98.

\section{TABLES}

\section{TABLE 1 Summary Statistics of Block Trades in the London Stock Exchange}

This table reports summary statistics in millions of pounds for all block trades defined as trades of 10,000 shares or more executed on the London Stock Exchange in 2010.

\begin{tabular}{|l|ll|}
\hline Block Trade & Buy & Sell \\
\hline Number of Block Trades (£ million) & 1.23 & 1.094 \\
\hline Mean (£ thousand) & 42.987 & 40.123 \\
\hline Medium (£ thousand) & 37.826 & 34.675 \\
\hline Minimum (£ thousand) & 10 & 10 \\
\hline Maximum (£ million) & 13.6 & 15.4 \\
\hline Standard Deviation (£ thousand) & 36.1 & 37.1 \\
\hline Average Block Value (£ million) & 4.33 & 4.66 \\
\hline $\begin{array}{l}\text { Number of Trades of all Sizes } \\
\text { (£ million) }\end{array}$ & 1.98 & 1.84 \\
\hline
\end{tabular}

\section{TABLE 2. Block Trade Size Distribution in the London Stock Exchange}

This table reports the cumulative distribution of all block trades defined as trades of 10,000 shares or more executed on the London Stock Exchange in 2010.

\begin{tabular}{lll}
\hline No of Trades & Percentage of Total Block Trades & Cumulative Percentage \\
\hline $10,000-20,000$ & 40 & 40 \\
$20,000-50,000$ & 30 & 70 \\
\hline
\end{tabular}




\begin{tabular}{lll}
\hline $50,000-100,000$ & 5 & 75 \\
$100,000-500,000$ & 7 & 82 \\
$500,000-1,000,000$ & 10 & 92 \\
\hline$>1,000,000$ & 8 & 100 \\
\hline
\end{tabular}

\section{TABLE 3: Heterogeneous Liquidity Effects of Block Trade Sizes on the London Stock Exchange}

The specification is $S_{j, i}=\lambda_{0 i}+\lambda_{1}$ Size $_{i}+\lambda_{2} P_{i}+\lambda_{3} M_{i}^{v}+\lambda_{4} V_{i}^{o l}+\varepsilon_{i}$. Where, $S_{j}$ denotes the different measures of market liquidity $(j=1, . ., 3)$; and $i$ represents each block trade that was executed on the LSE in 2010 . We proxy market liquidity through three measures of bid-ask spread, namely, the relative bid-ask spread, the effective bid-ask spread and the Huang and Stoll (1997) measure of the adverse selection cost component of bid-ask spread. Size, $\mathrm{P}, \mathrm{M}^{\mathrm{V}}$ and $\mathrm{V}^{\mathrm{OL}}$ correspondingly denote block size, share prices, market value of the company, and stock market volatility. Share price is the execution price of the block trade; firm size is the market value of the firm's common equity; stock market volatility is proxied by the rolling (fortnightly) standard deviation of stock return. All the variables are expressed in natural logarithms in order to minimize the impact of excess skewness and kurtosis in the data. The cross-size parameter equality (i.e., the equality of $\lambda$ s across the categories of different block sizes) is tested by the standard (Chow type) Ftests, and error variance equality across the different trade size categories is conducted with the use of Lagrange Multiplier (LM) tests of homogeneity. Figures in brackets represent the $p$-values of the F and chi squared statistics, which are obtained through bootstrap simulations, given the lack of availability of suitable critical values from statistical tables due to our large sample size. ${ }^{*}$ denote statistical significance at all conventional levels.

Panel A. Parameter Equality (F Test)

\begin{tabular}{|llll|}
\hline No of Trades & $\begin{array}{l}\text { Relative } \\
\text { Spread }\end{array}$ & $\begin{array}{l}\text { Effective } \\
\text { Spread }\end{array}$ & $\begin{array}{l}\text { Adverse } \\
\text { Selection }\end{array}$ \\
\hline $10,000-20,000$ & $25.32(0.63)$ & $29.32(0.55)$ & $34.56(0.50)$ \\
\hline $20,000-50,000$ & $34.65(0.77)$ & $38.99(0.50)$ & $42.30(0.42)$ \\
\hline$>50,000$ & $2740(0.00)^{*}$ & $2813(0.00)^{*}$ & $2870(0.00)^{*}$ \\
\hline
\end{tabular}

Panel B. Parameter Variance Equality (LM Test)

\begin{tabular}{|llll|}
\hline No of Trades & $\begin{array}{l}\text { Relative } \\
\text { Spread }\end{array}$ & $\begin{array}{l}\text { Effective } \\
\text { Spread }\end{array}$ & $\begin{array}{l}\text { Adverse } \\
\text { Selection }\end{array}$ \\
\hline $10,000-20,000$ & $32.43(0.58)$ & $39.44(0.50)$ & $44.66(0.48)$ \\
\hline
\end{tabular}




\begin{tabular}{|llll|}
\hline $20,000-50,000$ & $33.88(0.72)$ & $40.21(0.58)$ & $46.39(0.48)$ \\
\hline$>50,000$ & $3343(0.00)^{*}$ & $3013(0.00)^{*}$ & $3170(0.00)^{*}$ \\
\hline
\end{tabular}

\section{TABLE 4: Heterogeneous Liquidity Effects of Large Block Trade Sizes on the London Stock Exchange}

The specification is $S_{j, i}=\lambda_{0 i}+\lambda_{1}$ Size $_{i}+\lambda_{2} P_{i}+\lambda_{3} M_{i}^{v}+\lambda_{4} V_{i}^{o l}+\varepsilon_{i}$. Where, $S_{j}$ denotes the different measures of market liquidity $(j=1, . ., 3)$; and i represents each block trade that was executed on the LSE in 2010. We proxy market liquidity through three measures of bid-ask spread, namely, the relative bid-ask spread, the effective bid-ask spread and the Huang and Stoll (1997) measure of the adverse selection cost component of bid-ask spread. Size, $\mathrm{P}, \mathrm{M}^{\mathrm{V}}$ and $\mathrm{V}^{\mathrm{OL}}$ correspondingly denote block size, share prices, market value of the company, and stock market volatility. Share price is the execution price of the block trade; firm size is the market value of the firm's common equity; stock market volatility is proxied by the rolling (fortnightly) standard deviation of stock return. All the variables are expressed in natural logarithms in order to minimize the impact of excess skewness and kurtosis in the data. The cross-size parameter equality (i.e., the equality of $\lambda s$ across the categories of different block sizes) is tested by the standard (Chow type) Ftests, and error variance equality across the different trade size categories is conducted with the use of Lagrange Multiplier (LM) tests of homogeneity. Figures in brackets represent the $p$-values of the $\mathrm{F}$ and chi squared statistics, which are obtained through bootstrap simulations, given the lack of availability of suitable critical values from statistical tables due to our large sample size. ${ }^{*}$ denote statistical significance at all conventional levels.

Panel A. Parameter Equality (F Test)

\begin{tabular}{|llll|}
\hline No of Trades & $\begin{array}{l}\text { Relative } \\
\text { Spread }\end{array}$ & $\begin{array}{l}\text { Effective } \\
\text { Spread }\end{array}$ & $\begin{array}{l}\text { Adverse } \\
\text { Selection }\end{array}$ \\
\hline $50,000-100,000$ & $17.63(0.77)$ & $19.32(0.70)$ & $25.56(0.62)$ \\
\hline $100,000-500,000$ & $22.65(0.82)$ & $30.24(0.58)$ & $38.40(0.46)$ \\
\hline $500,000-1000000$ & $22.98(0.74)$ & $25.56(0.76)$ & $27.89(0.80)$ \\
\hline$>1000000$ & $24.56(0.72)$ & $22.34(0.76)$ & $20.12(0.84)$ \\
\hline
\end{tabular}

Panel B. Parameter Variance Equality (LM Test)

\begin{tabular}{|c|c|c|c|}
\hline No of Trades & Relative & Effective & Adverse \\
\hline
\end{tabular}




\begin{tabular}{|llll|}
\hline & Spread & Spread & Selection \\
\hline $50,000-100,000$ & $22.43(0.64)$ & $39.44(0.50)$ & $44.66(0.48)$ \\
\hline $100,000-500,000$ & $30.80(0.70)$ & $32.21(0.72)$ & $32.00(0.55)$ \\
\hline $500,000-1000000$ & $33.43(0.64)$ & $30.10(0.60)$ & $30.56(0.61)$ \\
\hline$>1000000$ & $20.22(0.80)$ & $18.30(0.79)$ & $20.98(0.85)$ \\
\hline
\end{tabular}

\section{TABLE 5: Liquidity Effects and Small Block Trade Sizes on the London Stock Exchange}

The specification is $S_{j, i}=\lambda_{0 i}+\lambda_{1}$ Size $_{i}+\lambda_{2} P_{i}+\lambda_{3} M_{i}^{v}+\lambda_{4} V_{i}^{o l}+\varepsilon_{i}$. Where, $S_{j}$ denotes the different measures of market liquidity $(\mathrm{j}=1, \ldots, 3)$; and $\mathrm{i}$ represents each block trade that was executed on the LSE in 2010. We proxy market liquidity through three measures of bid-ask spread, namely, the relative bid-ask spread, the effective bid-ask spread and the Huang and Stoll (1997) measure of the adverse selection cost component of bid-ask spread. Size, $\mathrm{P}, \mathrm{M}^{\mathrm{V}}$ and $\mathrm{V}^{\mathrm{OL}}$ correspondingly denote block size, share prices, market value of the company, and stock market volatility. Share price is the execution price of the block trade; firm size is the market value of the firm's common equity; stock market volatility is proxied by the rolling (fortnightly) standard deviation of stock return. SE is the standard error of the regression and Norm (2) is the Jacque Bera normality test of the residuals. All the variables are expressed in natural logarithms in order to minimize the impact of excess skewness and kurtosis in the data. Figures in brackets are $p$-values and * denote statistical significance at all conventional levels.

Panel A. Block Trade Size, 10,000-20,000 Shares

\begin{tabular}{llll}
\hline Regressors & Relative Spread & Effective Spread & Adverse Selection \\
\hline$\lambda_{0 i}$ & 0.004 & 0.121 & 0.133 \\
$\lambda_{1}$ & $(0.00)^{*}$ & $(0.00)^{*}$ & $(0.00)^{*}$ \\
$\lambda_{2}$ & -0.125 & -0.134 & -0.140 \\
$\lambda_{3}$ & $(0.00)^{*}$ & $(0.00)^{*}$ & $(0.00)^{*}$ \\
$\lambda_{4}$ & -0.690 & -0.888 & -0.922 \\
$\bar{R}^{2}$ & $(0.00)^{*}$ & $(0.00)^{*}$ & $(0.00)^{*}$ \\
SE & -0.122 & -0.234 & -0.301 \\
NORM (2) & $(0.00)^{*}$ & $(0.00)^{*}$ & $(0.00)^{*}$ \\
\hline
\end{tabular}


Panel B. Block Trade Size, 20,000-50,000 Shares

\begin{tabular}{llll}
\hline Regressors & Relative Spread & Effective Spread & Adverse Selection \\
\hline$\lambda_{0 i}$ & 0.009 & 0.133 & 0.124 \\
$\lambda_{1}$ & $(0.00)^{*}$ & $(0.00)^{*}$ & $(0.00)^{*}$ \\
$\lambda_{2}$ & -0.173 & -0.155 & -0.132 \\
& $(0.00)^{*}$ & $(0.00)^{*}$ & $(0.00)^{*}$ \\
$\lambda_{3}$ & -0.822 & -0.732 & -0.833 \\
$\lambda_{4}$ & $(0.00)^{*}$ & $(0.00)^{*}$ & $(0.00)^{*}$ \\
$\bar{R}^{2}$ & -0.133 & -0.133 & -0.222 \\
SE & $(0.00)^{*}$ & $(0.00)^{*}$ & $(0.00)^{*}$ \\
NORM (2) & 0.099 & 0.077 & 0.044 \\
\hline
\end{tabular}

\section{TABLE 6: Liquidity Effects and Large Block Trade Sizes on the London Stock Exchange}

The specification is $S_{j, i}=\lambda_{0 i}+\lambda_{1} S_{\text {Size }}+\lambda_{2} P_{i}+\lambda_{3} M_{i}^{v}+\lambda_{4} V_{i}^{o l}+\varepsilon_{i}$. Where, $S_{j}$ denotes the different measures of market liquidity $(\mathrm{j}=1, . ., 3)$; and $\mathrm{i}$ represents each block trade that was executed on the LSE in 2010 . We proxy market liquidity through three measures of bid-ask spread, namely, the relative bid-ask spread, the effective bid-ask spread and the Huang and Stoll (1997) measure of the adverse selection cost component of bid-ask spread. Size, $\mathrm{P}, \mathrm{M}^{\mathrm{V}}$ and $\mathrm{V}^{\mathrm{OL}}$ correspondingly denote block size, share prices, market value of the company, and stock market volatility. Share price is the execution price of the block trade; firm size is the market value of the firm's common equity; stock market volatility is proxied by the rolling (fortnightly) standard deviation of stock return. SE is the standard error of the regression and Norm (2) is the Jacque Bera normality test of the residuals. All the variables are expressed in natural logarithms in order to minimize the impact of excess skewness and kurtosis in the data. Figures in brackets are $p$-values and * denote statistical significance at all conventional levels.

Panel A. Block Trade Size, 50,000-100,000 Shares

\begin{tabular}{llll}
\hline Regressors & Relative Spread & Effective Spread & Adverse Selection \\
\hline$\lambda_{0 i}$ & 0.333 & 0.226 & 0.356 \\
$\lambda_{1}$ & $(0.00)^{*}$ & $(0.00)^{*}$ & $(0.00)^{*}$ \\
$\lambda_{2}$ & 0.433 & 0.321 & 0.488 \\
& $(0.00)^{*}$ & $(0.00)^{*}$ & $(0.00)^{*}$ \\
$\lambda_{3}$ & -0.211 & -0.333 & -0.410 \\
$\lambda_{4}$ & $(0.00)^{*}$ & $(0.00)^{*}$ & $(0.00)^{*}$ \\
$\bar{R}^{2}$ & -0.243 & -0.356 & -0.421 \\
SE & $(0.00)^{*}$ & $(0.00)^{*}$ & $(0.00)^{*}$ \\
NORM $(2)$ & 0.088 & 0.032 & 0.022 \\
& $(0.00)^{*}$ & $(0.00)^{*}$ & $(0.00)^{*}$ \\
& 0.321 & 0.346 & 0.401 \\
& 0.566 & 0.433 & 0.300 \\
\end{tabular}

Panel B. Block Trade Size, 100,000-500,000 Shares 


\begin{tabular}{llll}
\hline Regressors & Relative Spread & Effective Spread & Adverse Selection \\
\hline$\lambda_{0 i}$ & 0.942 & 0.742 & 0.833 \\
$\lambda_{1}$ & $(0.00)^{*}$ & $(0.00)^{*}$ & $(0.00)^{*}$ \\
$\lambda_{2}$ & 0.611 & 0.400 & 0.780 \\
$\lambda_{3}$ & $(0.00)^{*}$ & $(0.00)^{*}$ & $(0.00)^{*}$ \\
$\lambda_{4}$ & -0.413 & -0.140 & -0.118 \\
$\bar{R}^{2}$ & $(0.00)$ & $(0.00)^{*}$ & $(0.00)^{*}$ \\
SE & -0.152 & -0.242 & -0.168 \\
NORM (2) & $(0.00)^{*}$ & $(0.00)^{*}$ & $(0.00)^{*}$ \\
\hline
\end{tabular}

Panel C. Block Trade Size, 500,000-1,000,000 Shares

\begin{tabular}{llll}
\hline Regressors & Relative Spread & Effective Spread & Adverse Selection \\
\hline$\lambda_{0 i}$ & 0.014 & 0.450 & 0.017 \\
$\lambda_{1}$ & $(0.00)^{*}$ & $(0.00)^{*}$ & $(0.00)^{*}$ \\
$\lambda_{2}$ & 0.788 & 0.823 & 0.924 \\
$\lambda_{3}$ & $(0.00)^{*}$ & $(0.00)^{*}$ & $(0.00)^{*}$ \\
$\lambda_{4}$ & -0.290 & -0.303 & -0.285 \\
$\bar{R}^{2}$ & $(0.00)^{*}$ & $(0.00)^{*}$ & $(0.00)^{*}$ \\
SE & -0.078 & -0.114 & -0.071 \\
NORM (2) & $(0.00)^{*}$ & $(0.00)^{*}$ & $(0.00)^{*}$ \\
\hline
\end{tabular}

Panel D. Block Trade Size, > 1,000,000 Shares

\begin{tabular}{llll}
\hline Regressors & Relative Spread & Effective Spread & Adverse Selection \\
\hline$\lambda_{0 i}$ & 0.033 & 0.058 & 0.110 \\
$\lambda_{1}$ & $(0.00)^{*}$ & $(0.00)^{*}$ & $(0.00)^{*}$ \\
$\lambda_{2}$ & 1.157 & 1.263 & 1.376 \\
$\lambda_{3}$ & $(0.00)^{*}$ & $(0.00)^{*}$ & $(0.00)^{*}$ \\
$\lambda_{4}$ & -0.485 & -0.521 & -0.601 \\
$\bar{R}^{2}$ & $(0.00)^{*}$ & $(0.00)^{*}$ & $(0.00)^{*}$ \\
$\mathrm{SE}$ & -0.716 & -0.824 & -0.967 \\
\hline
\end{tabular}


